\title{
The regional aerosol-climate model REMO-HAM
}

\author{
J.-P. Pietikäinen ${ }^{1,2,3}$, D. O’Donnell ${ }^{1}$, C. Teichmann ${ }^{2,3}$, U. Karstens ${ }^{4}$, S. Pfeifer ${ }^{3}$, J. Kazil ${ }^{5,6}$, R. Podzun ${ }^{2,3, \dagger}$, S. Fiedler ${ }^{7}$, \\ H. Kokkola ${ }^{1}$, W. Birmili ${ }^{8}$, C. O'Dowd ${ }^{9}$, U. Baltensperger ${ }^{10}$, E. Weingartner ${ }^{10}$, R. Gehrig ${ }^{11}$, G. Spindler ${ }^{7}$, \\ M. Kulmala ${ }^{12}$, J. Feichter ${ }^{2}$, D. Jacob ${ }^{2,3}$, and A. Laaksonen ${ }^{1,13}$ \\ ${ }^{1}$ Finnish Meteorological Institute, P.O. Box 503, 00101 Helsinki, Finland \\ ${ }^{2}$ Max Planck Institute for Meteorology, Bundesstrasse 53, 20146 Hamburg, Germany \\ ${ }^{3}$ Climate Service Center, Chilehaus - Eingang B, Fischertwiete 1, 20095 Hamburg, Germany \\ ${ }^{4}$ Max Planck Institute for Biogeochemistry, Hans-Knöll-Straße 10, 07745 Jena, Germany \\ ${ }^{5}$ Cooperative Institute for Research in Environmental Sciences (CIRES), University of Colorado, \\ 325 Broadway R/CSD, Boulder, Colorado, USA \\ ${ }^{6}$ NOAA Earth System Research Laboratory (ESRL), 325 Broadway CO 80305-3337, Boulder, Colorado, USA \\ ${ }^{7}$ Institute for Climate and Atmospheric Science, University of Leeds, LS2 9JT, Leeds, UK \\ ${ }^{8}$ Leibniz Institute for Tropospheric Research (IfT), Permoserstr. 15, 04318 Leipzig, Germany \\ ${ }^{9}$ National University of Ireland Galway, University Road, Galway, Ireland \\ ${ }^{10}$ Laboratory of Atmospheric Chemistry, Paul Scherrer Institute, 5232 Villigen PSI, Switzerland \\ ${ }^{11}$ Empa - Swiss Federal Laboratories for Materials Science and Technology, Überlandstrasse 129, \\ 8600 Dübendorf, Switzerland \\ ${ }^{12}$ Department of Physics, University of Helsinki, P.O. Box 44, 00014 Helsinki, Finland \\ ${ }^{13}$ Department of Applied Physics, University of Eastern Finland, P.O. Box 1627, 70211 Kuopio, Finland \\ $\dagger$ Deceased in September 2011
}

Correspondence to: J.-P. Pietikäinen (joni-pekka.pietikainen@ @ fmi.fi)

Received: 24 February 2012 - Published in Geosci. Model Dev. Discuss.: 26 March 2012

Revised: 3 October 2012 - Accepted: 8 October 2012 - Published: 1 November 2012

\begin{abstract}
REMO-HAM is a new regional aerosol-climate model. It is based on the REMO regional climate model and includes most of the major aerosol processes. The structure for aerosol is similar to the global aerosol-climate model ECHAM5-HAM, for example the aerosol module HAM is coupled with a two-moment stratiform cloud scheme. On the other hand, REMO-HAM does not include an online coupled aerosol-radiation nor a secondary organic aerosol module. In this work, we evaluate the model and compare the results against ECHAM5-HAM and measurements. Four different measurement sites were chosen for the comparison of total number concentrations, size distributions and gas phase sulfur dioxide concentrations: Hyytiälä in Finland, Melpitz in Germany, Mace Head in Ireland and Jungfraujoch in Switzerland. REMO-HAM is run with two different resolutions: $50 \times 50 \mathrm{~km}^{2}$ and $10 \times 10 \mathrm{~km}^{2}$. Based on our simulations, REMO-HAM is in reasonable agreement with the measured values. The differences in the total number concentrations
\end{abstract}

between REMO-HAM and ECHAM5-HAM can be mainly explained by the difference in the nucleation mode. Since we did not use activation nor kinetic nucleation for the boundary layer, the total number concentrations are somewhat underestimated. From the meteorological point of view, REMOHAM represents the precipitation fields and $2 \mathrm{~m}$ temperature profile very well compared to measurement. Overall, we show that REMO-HAM is a functional aerosol-climate model, which will be used in further studies.

\section{Introduction}

Aerosol particles have an important role in the climate system. They have the ability to scatter and absorb both solar and thermal radiation. These processes are referred to as the direct effect of aerosols (Haywood and Boucher, 2000). Absorbing aerosol particles can also heat the surrounding air, 
which can lead to evaporation of cloud droplets. This effect is known as the semi-direct effect (Hansen et al., 1997). Finally, the ability to act as cloud condensation nuclei (CCN) and ice nuclei (IN) is referred to as the indirect effect of aerosol particles (Lohmann and Feichter, 2005). The indirect effect is usually divided into two parts: the cloud albedo effect (an increase in aerosol concentrations leads to an increase in cloud droplets, which increases the albedo) and the cloud lifetime effect (increase in aerosol concentrations leads to smaller droplets, which reduces precipitation efficiency and prolong the cloud lifetime). Aerosol effects have been widely studied experimentally and with models. However, the uncertainties of aerosol-cloud interactions still remains quite high (IPCC, 2007).

Aerosol particles originate both from natural and anthropogenic sources (Seinfeld and Pandis, 1998). Tropospheric aerosol particles are either formed from the gas phase through nucleation and growth, or directly emitted from the surface of the Earth. Downward mixing of aerosol particles from the stratosphere has a minor contribution to tropospheric aerosol loads. Kulmala et al. (2004) showed that nucleation events occur frequently around the globe and that nucleation has a significant role in global and regional $\mathrm{CCN}$ concentrations. Major sources of emitted particles are oceans, arid and semi-arid regions, volcanoes, wildfires and combustion of fossil and biomass fuels (Dentener et al., 2006).

Many of the aerosol processes have strong regional characteristics. Sogacheva et al. $(2005,2007)$ showed that nucleation events occur more frequently in Hyytiälä, Finland, if the incoming air masses come from the Arctic Ocean rather than from Central Europe. This is interesting, because nucleation is a frequent process in Central Europe, and it is not known what suppresses nucleation when air flows towards Scandinavia. Atmospheric dynamics influence the properties of aerosol particles, but on the other hand, local aerosol processes change the number concentrations and size distributions, which in turn influences the dynamics. Laaksonen et al. (2005) showed that in the Po Valley, Italy, nucleation may contribute up to a third to the regional $\mathrm{CCN}$ budget. Moreover, Raatikainen et al. (2010) reported that the aerosol particle volume increases with increasing population along the parcel trajectory. This shows the importance of emissions to atmospheric aerosol properties.

Aerosol effects on warm clouds have been considered in climate models for many years (Jones et al., 1994). The first climate models used sulfate aerosols as a surrogate for all anthropogenic aerosols. During the development of the climate models, the major global aerosol components (such as sulfate, particulate organic matter, black carbon, sea salt and mineral dust) have been included, e.g. in ECHAM by Stier et al. (2005). Different approaches to describe the aerosol distribution have been implemented, such as in ECHAM modal representation by Stier et al. (2005) and a sectional representation by Kokkola et al. (2008). Aerosol modules are used in global (Stier et al., 2005) and regional (Zubler et al., 2011a) climate models with a coupling to the models' cloud scheme (Lohmann et al., 2007).

Recently, many modeling efforts have been made to study the aerosol-cloud interactions on different scales. Just to list a few, Stier et al. (2005) presented the global aerosol-climate model ECHAM5-HAM and showed how well the model performs on global scale. Spracklen et al. (2006) used an offline version of a global aerosol model to study the contribution of boundary layer nucleation to particle concentrations. Lohmann et al. (2007) coupled the ECHAM5-HAM aerosol model with a large scale cloud scheme and studied the anthropogenic aerosol effects on the global scale. More detailed process studies (nucleation and secondary organics) with ECHAM5-HAM were carried out by Makkonen et al. (2009) and O'Donnell et al. (2011). Using a global aerosol microphysics model GLOMAP, Spracklen et al. (2010) studied the aerosol concentrations from various sites around the world. They showed, among other things, that continental boundary layer nucleation is an important process when trying to model the measured concentration. Yu et al. (2012) used the global chemistry transport model GEOS-Chem and the regional weather forecasting and chemistry model WRFChem, both with an advanced particle microphysics (APM) model, to calculate and investigate global and regional distributions of aerosol optical properties. On a regional scale, coupled aerosol-chemistry interactions were studied with the REMOTE model by Langmann et al. (2008). They showed the importance of emission sources for the regional scale concentrations. Finally, Zubler et al. (2011a) made simulations with the COSMO-CLM regional model in which they implemented the aerosol module HAM. This study showed how useful the regional aerosol-climate model is for studies of mesoscale phenomena.

The heavy computational load of aerosol physics and chemistry remains a major problem when modeling global and regional aerosol characteristics. Aerosol models need many species to be included even if only the main species are treated (Stier et al., 2005; Spracklen et al., 2006). This still limits the resolution of the models, although some parts of the widely used aerosol and chemistry modules have been kept simple (Feichter et al., 1996; Reddington et al., 2011). For example, Weigum et al. (2012) showed that black carbon plumes over the Pacific Ocean typically occur at scales smaller than global climate model resolution. In order to capture the regional characteristics, regional models can be used as a framework (Langmann et al., 2008; Langmann, 2000; Zubler et al., 2011a). This approach allows us to see, for example, how well the implemented aerosol physics and chemistry modules perform on smaller spatial scales. In a way, this can be seen as an intermediate step between fine scale process models and global scale climate models. This makes regional aerosol-climate models a very interesting tool to study phenomena like nucleation, particle growth, coagulation, deposition etc., and to get more detailed information 
on (locally) important species, such as black carbon and sulfur. Moreover, we can also study how well the local emission sources are represented in the databases and how they effect every day life, for example in air quality studies (e.g. Teichmann, 2010).

In this work, we present the new regional aerosol-climate model REMO-HAM, which is suitable for studying aerosolcloud-interactions on a regional scale. It is based on the REMO regional climate model by Jacob and Podzun (1996). REMO can be used down to $10 \times 10 \mathrm{~km}^{2}$ resolution due to the hydrostatic limitation of the dynamical core. In this paper, we evaluate the REMO-HAM model against measurements, and compare it against the global aerosol-climate model ECHAM5-HAM.

\section{Model description}

\subsection{General Circulation Model ECHAM5-HAM}

The global climate model ECHAM5-HAM (Roeckner et al., 2003; Stier et al., 2005) is used in this study to provide lateral aerosol boundary data for the regional model simulations, and to provide data for model comparison. ECHAM5-HAM includes the aerosol module HAM (Stier et al., 2005), which uses the aerosol microphysical module M7 (Vignati et al., 2004). The aerosol model is coupled with a double-moment cloud scheme (e.g. Lohmann et al., 2007). In the following sections, more detailed information about the different modules will be provided.

\subsection{The REMO model}

The regional model REMO is a hydrostatic, threedimensional atmosphere model, that has been developed at the Max Planck Institute for Meteorology in Hamburg. It is based on the Europa Model, the former numerical weather prediction model of the German Weather Service (for more details, see Jacob and Podzun, 1996; Jacob, 2001). REMO can be used for spatial resolutions from $10 \times 10 \mathrm{~km}^{2}$ upwards. The limitation comes from the dynamical core, which is hydrostatic (REMO also has a non-hydrostatic extension to the hydrostatic core, but it was not used in this study). The physical core of REMO is based on the physical package of the global circulation model ECHAM4 (Roeckner et al., 1996). Prognostic variables are the horizontal wind components, surface pressure, temperature, specific humidity, cloud liquid water and ice. The vertical levels in REMO are represented in a hybrid sigma-pressure coordinate system. Hybrid coordinates follow the surface orography in the lower levels and become independent from surface orography at higher atmospheric model levels.

In REMO, the stratiform (large-scale) cloud scheme is based on the original ECHAM4 cloud scheme (for details see Roeckner et al., 1996) and has been updated following ECHAM5 by Pfeifer (2003). The scheme includes prognostic equations for cloud water, water vapor and cloud ice, and has an empirical cloud cover scheme by Sundqvist et al. (1989). The cloud droplet number concentration is parameterized separately for continental and maritime climate, and is a function of height (Roeckner et al., 1996).

The convective (sub-grid) cloud parameterization is based on the mass-flux scheme from Tiedke (1989) with modifications by Nordeng (1994). Pfeifer (2003) also included a new type of convection to the cloud scheme, the so called cold convection. This type of convection might occur in cold air outbreaks over sea in the extra tropical atmosphere.

REMO does not include an aerosol module. The information about aerosols, for example in the radiation scheme, is based on the climatology from Tanre et al. (1984). In this climatology, the spatial distributions of the optical thickness of land, sea, urban, and desert aerosols, and well mixed tropospheric and stratospheric background aerosols are represented. The climatology is based on a global T10 spectral distribution $(\approx 1300 \mathrm{~km}$, fixed in time) and the aerosols in this climatology have no direct influence on the clouds, that is, the indirect aerosol effects are not represented. The climatology is highly absorbing, mainly over Africa and in Southern and Eastern Europe (Zubler et al., 2011b). The reason for this is the unrealistic dust component, which dominates the aerosol optical depth over these areas. In addition, the low resolution of the climatology is problematic, especially on regional scales. This is a known deficiency of the current model version and a new radiation scheme (coupled with HAM aerosol module) will be implemented.

\subsection{Aerosol physics and chemistry}

HAM is an aerosol chemistry and physics model, which predicts the evolution of an ensemble of microphysically interacting internally- and externally-mixed aerosol populations as well as their size-distribution and composition. HAM uses the aerosol microphysics module M7 in which the size-distribution is represented by a superposition of seven log-normal modes. HAM itself has all the main aerosol processes: water uptake, chemistry (gas- and liquid phase), emissions, sedimentation, deposition (wet and dry) and cloud processes (scavenging). The M7 microphysical core includes the following processes: coagulation, condensation, nucleation, thermodynamic equilibrium with water vapor and inter modal transfer. A detailed description of the HAM model can be found in Stier et al. (2005), and for more information about M7, see Vignati et al. (2004). In the following, we will present the main features of the aerosol model.

The seven log-normal modes are: soluble and insoluble Aitken, accumulation, and coarse modes, and one soluble nucleation mode. Table 1 shows how HAM treats different species. The five aerosol components considered in HAM are sulfate, black carbon, organic carbon, sea salt and mineral dust. These components are divided into different modes as shown in Table 1. The aerosol dynamics, e.g. coagulation, 
Table 1. The modal structure of HAM. $N_{i}$ denotes the aerosol number of mode $i, M_{i}^{j}$ denotes the mass of compound $j, \mathrm{~S}$ means sulfur, BC means black carbon, POM means primary organic matter (OC), DU means dust and SS means sea salt. The dry radius $r$ shows the limits of different modes (Stier et al., 2005).

\begin{tabular}{lcc}
\hline Mode & Soluble/Mixed & Insoluble \\
\hline $\begin{array}{l}\text { Nucleation mode } \\
r \leq 5 \mathrm{~nm}\end{array}$ & $N_{1}, \mathrm{M}_{1}^{\mathrm{S}}$ & \\
\hline $\begin{array}{l}\text { Aitken mode } \\
5 \mathrm{~nm}<r \leq 50 \mathrm{~nm}\end{array}$ & $N_{2}, \mathrm{M}_{2}^{\mathrm{S}}, M_{2}^{\mathrm{BC}}, M_{2}^{\mathrm{POM}}$ & $N_{5}, M_{5}^{\mathrm{BC}}, M_{5}^{\mathrm{POM}}$ \\
\hline $\begin{array}{l}\text { Accumulation mode } \\
50 \mathrm{~nm}<r \leq 0.5 \mu \mathrm{m}\end{array}$ & $N_{3}, M_{3}^{\mathrm{S}}, M_{3}^{\mathrm{BC}}, \mathrm{M}_{3}^{\mathrm{POM}}, M_{3}^{\mathrm{SS}}, \mathrm{M}_{3}^{\mathrm{DU}}$ & $N_{6}, M_{6}^{\mathrm{DU}}$ \\
\hline $\begin{array}{l}\text { Coarse mode } \\
0.5 \mu \mathrm{m}<r\end{array}$ & $N_{4}, M_{4}^{\mathrm{S}}, M_{4}^{\mathrm{BC}}, M_{4}^{\mathrm{POM}}, M_{4}^{\mathrm{SS}}, M_{4}^{\mathrm{DU}}$ & $N_{7}, M_{7}^{\mathrm{DU}}$ \\
\hline
\end{tabular}

can change the composition of each internally mixed mode. HAM has two water uptake methods: calculating the equilibrium liquid water content of the aerosol using the ZSR method (Jacobson et al., 1996), and the second is based on Kappa-Köhler theory (Petters and Kreidenweis, 2007; O'Donnell et al., 2011). In this work, the latter is used.

In the framework of this work, four different nucleation schemes are included. The binary sulfuric acid - water based nucleation methods are by Vehkamäki et al. (2002) and Kazil and Lovejoy (2007). Furthermore, two nucleation methods are implemented for the forested boundary layer: nucleation based on cluster activation following Kulmala et al. (2006) and nucleation based on kinetic activation following Laakso et al. (2004). Newly formed particles (number and mass) are placed in the nucleation mode. Nucleation is restricted to happen only in the cloud-free portions of the model grid boxes. In cloudy portions, sulfuric acid is removed by condensation. For simulations presented in this work, we are only using the nucleation scheme by Kazil and Lovejoy (2007).

In our current setup, we use a sulfate aerosol chemistry module described by Feichter et al. (1996). In this approach, dimethyl sulfide (DMS), sulfur dioxide $\left(\mathrm{SO}_{2}\right)$ and sulfate $\left(\mathrm{SO}_{4}^{2-}\right)$ are treated as prognostic variables. We use three dimensional monthly mean oxidant fields for hydroxyl $(\mathrm{OH})$, hydrogen peroxide $\left(\mathrm{H}_{2} \mathrm{O}_{2}\right)$, ozone $\left(\mathrm{O}_{3}\right)$ and nitrogen dioxide $\left(\mathrm{NO}_{2}\right)$ (Stier et al., 2005). These fields originate from the calculations of the comprehensive MOZART chemical transport model (Horowitz et al., 2003). This decision was made, because in this work we want to minimize the setup differences for the analysis part. However, this approach lowers the accuracy of the higher resolution model in terms of the chemistry. Higher resolution oxidation fields should be used in the future, or the online chemical transport version of REMO by Teichmann (2010) in a coupled mode.

The chemical module in our current version calculates the oxidation in the gas- and aqueous phase. In the gas phase, $\mathrm{SO}_{2}$ and DMS are oxidized by $\mathrm{OH}$ during the daytime, and
DMS reacts with the nitrate radical $\left(\mathrm{NO}_{3}\right)$ during nighttime. $\mathrm{NO}_{3}$ is assumed to be in steady state with its production and loss terms, which both include reactions with $\mathrm{NO}_{2}$. The reactions of $\mathrm{O}_{3}, \mathrm{SO}_{2}$ and $\mathrm{H}_{2} \mathrm{O}_{2}$ are considered in the aqueous phase. The gas phase sulfuric acid concentration is calculated with an improved time integration scheme by Kokkola et al. (2009). As the oxidant fields are on a monthly time resolution, an artificial diurnal cycle for $\mathrm{OH}$ has been used. In this approach, the $\mathrm{OH}$ concentrations follow a cosine peak between sunrise and sunset. The peak amplitude has been scaled with day length so that the original monthly mean values are preserved. The same approach is also used in ECHAM5-HAM.

At the moment, the aerosol information from HAM is not coupled with the radiation scheme in REMO. ECHAM5HAM has a radiation model, which includes the necessary physics for aerosols. We will update the radiation module of REMO(-HAM) in the future so that aerosols are also included.

\subsubsection{Emissions used in the model}

The emission module is based on the AEROCOM emission inventory for the year 2000 excluding sea salt (SS) emissions and dimethyl sulfide (DMS) emissions (Dentener et al., 2006). The sea salt emissions are based on the approach by Stier et al. (2005). In this approach, the emissions of sea salt particles are based on a look-up table for wind speeds between 1 and $40 \mathrm{~m} \mathrm{~s}^{-1}$. All the emitted species, except the sulfur compounds, are treated as primary emissions (emitted directly). In addition, the DMS emissions from the marine biosphere are calculated based on DMS sea water concentrations using an air-sea exchange rate. This is calculated using the model $10 \mathrm{~m}$ wind speed. Terrestrial biogenic emissions of DMS are prescribed (for details of both DMS emission schemes, see Stier et al., 2005).

The AEROCOM emissions are presented on a $1^{\circ} \times 1^{\circ}$ global grid. This is not an ideal accuracy REMO-HAM, but 
for the validation of the model, it has been used in this work. We do want to point out that higher resolution emission datasets are available on global and regional scales, and that they can be easily used with REMO-HAM. For all of the AEROCOM compounds, the data is preprocessed using a 1st order conservative remapping method. The data is remapped to the grid used in REMO and read in once per modeled month. We assume homogeneous mixing across the model grid box for all aerosol species. The emissions are injected to the lowest model layer, except for biomass burning emissions, explosive and continuous volcanoes, and emissions coming from industry, shipping and power plants. For all of the vertically dependent emissions, the levels described by Dentener et al. (2006) are used. For detailed information of different AEROCOM species, see Dentener et al. (2006) or visit http://nansen.ipsl.jussieu.fr/AEROCOM/.

In the following, we describe the aerosol emission in the model. Details on the sources can be found in Dentener et al. (2006). For the mean radius and the standard deviation of different emission modes we have used the same values as in Stier et al. (2005). Sulfur (S) is divided between gas phase $(97.5 \%)$ and particles $(2.5 \%)$ as primary $\mathrm{SO}_{4}$ (sulfate). For industry, shipping and power plants emissions, $50 \%$ of the sulfate emissions are released to the accumulation mode and $50 \%$ to the coarse mode. The remaining sulfate emissions are divided between Aitken mode (50\%) and accumulation mode $(50 \%)$. Secondary Organic Aerosol (SOA) formation is based on prescribed biogenic monoterpene emissions assuming a fixed SOA yield (15\%), and that SOA formation takes place in the emitting grid box. The primary organic matter (POM) emissions are also released to organic carbon. The mass ratio of organic mass to organic carbon is $1.4 .65 \%$ of SOA and POM emissions are assumed to be soluble and $35 \%$ insoluble. The insoluble organic matter is released entirely to the Aitken mode. With the exception of the fire and fuel sectors, soluble organic matter is emitted as organic carbon and is divided between Aitken and accumulation modes (50\% in each). The fire POM emissions are released to the soluble accumulation mode and fuel emissions to the insoluble Aitken mode. All black carbon emissions are released to the insoluble Aitken mode. For dust emissions, we use prescribed AEROCOM mass fluxes. These fluxes are on a monthly scale and have separate fields for accumulation and coarse modes (the mode properties are the same as in M7 Vignati et al., 2004).

\subsection{Cloud microphysics}

The stratiform cloud scheme described in Sect. 2.2 calculates the number of cloud droplets separately for maritime and continental clouds. The calculation does not take into account the information about aerosols provided by the HAM aerosol module. One way to use the aerosol information is to use the approach by Lohmann and Roeckner (1996), where the cloud droplet concentration for continental and marine clouds is calculated from the aerosol sulfate mass. This approach corrects the values calculated by the normal scheme but still does not fully take into account the information provided by the aerosol module. In order to use the information in the stratiform clouds, we have implemented the double-moment cloud microphysics scheme by Lohmann et al. (2007). This scheme has prognostic equations for water vapor, cloud water and cloud ice. In addition, it has prognostic equations for cloud droplet number concentration (CDNC) and ice crystal number concentration (ICNC). For the cloud cover (fractional), we use the approach by Sundqvist et al. (1989), in which the relative humidity determines whether a cloud is formed in the grid box or not. The autoconversion of cloud droplets can be calculated with two different parameterizations: Beheng (1994) and Khairoutdinov and Kogan (2000). The cloud scheme also includes a cirrus parameterization from Lohmann and Kärcher (2002).

The new cloud scheme is fully coupled with the HAM aerosol module. To connect the information from the aerosol module to the $\mathrm{CCN}$ activation, the activation schemes from Lin and Leaitch (1997) and Abdul-Razzak and Ghan (2000) are implemented. In this study, the latter is used. To connect the calculated cloud droplet and ice crystal number concentrations to the radiation, the approach by Lohmann et al. (2007) for cloud droplets and the approach by Lohmann et al. (2008) for ice crystals are implemented. In these approaches, using the CDNC and ICNC information combined with the cloud liquid water/ice content, the effective radius of droplets/crystals is calculated and passed to the radiation.

\subsection{Tracer transport}

The model tracers undergo the following transport processes: transport in convective clouds, sedimentation, dry and wet deposition, vertical diffusion and vertical- and horizontal advection. The convective transport of tracers is based on the mass-flux scheme described in Sect. 2.2. The sedimentation velocity calculation is based on the Stokes velocity with the Cunningham slip-flow correction factor accounting for noncontinuum effects (Stier et al., 2005). The dry deposition is based on the same size-dependent parameterization as in the ECHAM5-HAM model (Stier et al., 2005). Current version of REMO-HAM does not include information about canopy height or soil $\mathrm{pH}$. For these, REMO-HAM uses the same prescribed fields as ECHAM-HAM. Other land surface parameters are directly from the model. For the wet deposition, we have implemented two different approaches for belowcloud aerosol scavenging. The first one, by Stier et al. (2005), can be used, but also the size dependent below-cloud scavenging by rain, or by rain and snow, by Croft et al. (2009) is introduced and used in this work. The vertical diffusion fluxes due to subgrid scale turbulence are calculated for the lowest layer (surface layer) according to Louis (1979). For the other layers, a second-order closure scheme by Mellor and Yamada (1974), is used. For the horizontal and vertical 
advection, we have implemented the finite difference, antidiffusive scheme proposed by Smolarkiewicz $(1984,1983)$. The scheme is mass conserving, positive definite and computationally efficient. The monotonicity is achieved by using higher order flux corrections. We also use two corrective steps (using anti-diffusion velocity) in order to decrease the numerical diffusion (for details, see Langmann, 2000; Smolarkiewicz, 1983, 1984).

ECHAM5-HAM and REMO-HAM included a slightly improved dry deposition scheme. The dry deposition scheme calculates dry deposition velocities separately for vegetated surface, wet skin, bare soil or snow, water and ice (Ganzeveld and Lelieveld, 1995; Ganzeveld et al., 1998). It is updated to use separate values of virtual potential temperature, roughness length and stability functions over land, water and ice rather than grid box averages of these quantities in the calculation of dry deposition velocities. (Actually the virtual potential temperature was erroneously taken from the value for land, which is assigned a default value over water or ice). This results in a significant strengthening of the dry deposition sink for some species, for example in ECHAM5-HAM, global dry deposition of $\mathrm{SO}_{2}$ increased from $17.6 \mathrm{Tg}(\mathrm{S}) \mathrm{yr}^{-1}$ before the changes to $20.8 \mathrm{Tg}(\mathrm{S}) \mathrm{yr}^{-1}$ afterwards (cf. a total emission flux of $\left.71 \mathrm{Tg}(\mathrm{S}) \mathrm{yr}^{-1}\right)$. We have used this updated scheme on all of the simulations done in this work.

\subsubsection{Lateral and upper boundary}

For the meteorology, the model uses the relaxation scheme by Davies (1976) at the lateral boundary. In this scheme, the eight outermost grid boxes are adjusted with an exponentially decreasing function. The influence of the large-scale driving fields decreases when moving towards the domain center. For the aerosol part, the lateral boundary treatment of tracers is implemented after Pleim et al. (1991). Due to discontinuities of the advection flux fields and the concentration fields at the boundaries, the lateral boundaries would have upstream reflections near the outflow boundary. The approach by Pleim et al. (1991) minimizes these discontinuities by setting the flux divergence to zero in the grid boxes next to the boundary.

We used the European Centre for Medium-Range Weather Forecasts $\left(\right.$ ECMWF) operational data set $\left(1.125^{\circ} \times 1.125^{\circ}\right)$ for the meteorological data at the model domain boundaries. The aerosol data is from ECHAM5-HAM which is run for the needed time period nudging (assimilation by linear relaxation) the model towards the ECMWF data. The ECHAM5-HAM global output is conservatively remapped to the REMO grid using the Climate Data Operators (CDO) program (https://code.zmaw.de/projects/cdo/). We have also done the remapping for the vertical levels due to the better representation of orography. In this work, we used 31 vertical levels for the models. In ECHAM5-HAM, the uppermost level reaches $10 \mathrm{hPa}$, and in REMO-HAM $20 \mathrm{hPa}$ is reached.

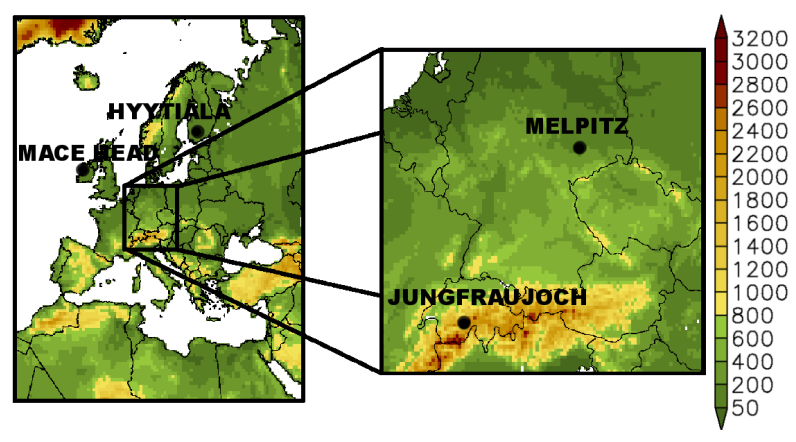

Fig. 1. The orographies of the domains used (in meters) and the selected CREATE database stations: Hyytiälä, Melpitz, Mace Head and Jungfraujoch. Shown on the left hand side is the $0.44^{\circ}$ resolution domain and on the right hand side the $0.088^{\circ}$ resolution domain.

\subsubsection{Dynamical downscaling}

The resolution of ECHAM5-HAM used in this study was T63L31 with a time step of $720 \mathrm{~s}$. This resolution corresponds to a resolution of $1.9^{\circ}$ (horizontally $210 \mathrm{~km}$ ). A jump from $1.9^{\circ}$ resolution to the resolution used in this study, $0.088^{\circ}\left(10 \times 10 \mathrm{~km}^{2}\right)$ is too large. In order to overcome this problem, dynamical downscaling was used (also known as the double-nesting method). In this method, the model is run with an intermediate resolution and the results from this simulation are used as boundary data for the higher resolution simulation. We used the resolution of $0.44^{\circ}\left(50 \times 50 \mathrm{~km}^{2}\right)$ for the intermediate step.

Figure 1 shows the orographies for the domains used in the dynamical downscaling process. The left figure represents the domain for the 1st step of dynamical downscaling. Using the data from this simulation, the model was run for the domain shown on the right hand side in Fig. 1.

\section{Measurement data}

We compare our results to measurement data from CREATE (Construction, use and delivery of an European aerosol database $)^{1}$ and EBAS $^{2}$ databases. From this dataset, we chose 4 different measurement sites: Hyytiälä (Finland $62^{\circ} \mathrm{N}$ and $24^{\circ} \mathrm{E}$ ), Melpitz (Germany $51^{\circ} \mathrm{N}$ and $13^{\circ} \mathrm{E}$ ), Mace Head (Ireland $53^{\circ} \mathrm{N}$ and $10^{\circ} \mathrm{W}$ ) and Jungfraujoch (Switzerland $47^{\circ} \mathrm{N}$ and $8^{\circ} \mathrm{E}$ ). From these stations, only the Melpitz and Jungfraujoch sites are within the $10 \mathrm{~km}$ resolution domain.

From the Hyytiälä (Dal Maso et al., 2005) and Melpitz (Birmili and Wiedensohler, 2000) stations we have used differential mobility particle sizer (DMPS) data for the total number concentrations and size distributions. The condensation particle counter (CPC) data was used for total number

\footnotetext{
${ }^{1}$ http://tarantula.nilu.no/projects/ccc/create/general_info.htm

${ }^{2}$ http://ebas.nilu.no
} 

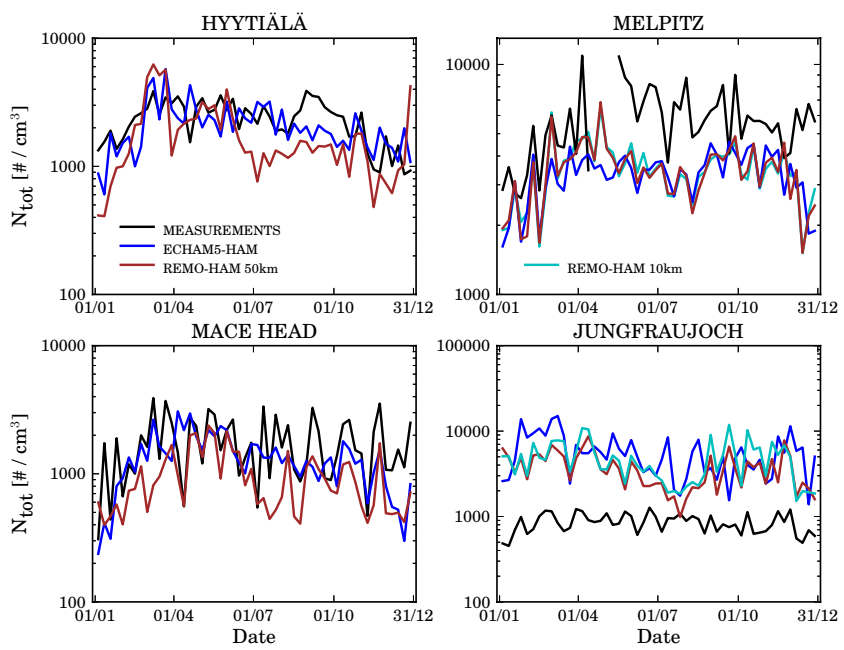

Fig. 2. The weekly mean total number concentrations from different measurements sites and models as a function of time.

concentration at Jungfraujoch (Collaud Coen et al., 2007; Collaud Coen and Weingartner, 2011) and at Mace Head (O'Connor et al., 2008). In addition, from Mace Head the aerosol size distributions were measured with a Scanning Mobility Particle Sizer (SMPS).

The gas phase $\mathrm{SO}_{2}$ concentrations are also compared against measurements. For Mace Head, there are no measurements of $\mathrm{SO}_{2}$. As a proxy for Mace Head, we use data from Valentia Observatory which is located approximately $150 \mathrm{~km}$ due southwest from the Mace Head measurement station (Bashir et al., 2006). The data from Valentia is daily filter data and should represent the concentrations from Mace Head reasonably well. The time resolution of one day was also used in the gas phase measurements from Jungfraujoch. For Hyytiälä and Melpitz, the gas phase data has a $30 \mathrm{~min}$ time resolution.

\section{Simulations and results}

The ECHAM5-HAM model was run for the time period of 1 July 2004-31 December 2005. The data output frequency used was $6 \mathrm{~h}$ and instantaneous values of the tracers were written out. From these results, the lateral tracer boundary data for REMO-HAM were processed, as described in Sect. 2.5.1. The REMO model was run for the time period of 1 October 2004-31 December 2005 for the $0.44^{\circ}$ $(50 \mathrm{~km})$ resolution with a time step of $240 \mathrm{~s}$, and 1 December 2004-31 December 2005 for the $0.088^{\circ}(10 \mathrm{~km})$ resolution using a $50 \mathrm{~s}$ time step. The model was run with the normal version (REMO) and with the aerosol module version (REMO-HAM). The time periods were chosen so that ECHAM5-HAM has 3 months of spin up time for the tracers, REMO/REMO-HAM with $50 \mathrm{~km}$ resolution has 2 months of spin up time and REMO/REMO-HAM with $10 \mathrm{~km}$ resolution has 1 month.

Of the four measurement sites, Jungfraujoch is the only one located in a mountainous area (the Alps) as can be seen from Fig. 1. In the case of Hyytiälä, Melpitz and Mace Head, the results from the models are from the lowest model layer. The mountainous location of Jungfraujoch (station at $3580 \mathrm{~m}$ height) makes the analysis different. The model orography for the Alpine region is flatter than in reality, especially in the case of ECHAM5-HAM. This means that the lowest model layer does not describe the actual measurement station altitude and instead the closest matching pressure level is chosen. The level is calculated separately for each of the models due to the different orography.

\subsection{Aerosol total number concentrations}

Figure 2 presents the measured and modelled weekly aerosol total number concentrations $\left(N_{\text {tot }}\right)$ for different measurement sites. We can see that for Hyytiälä ECHAM5-HAM is in reasonable agreement with the measured concentrations. The modelled values are slightly lower than measured, especially during late winter $\left(\Delta N_{\text {tot }}=1000 \# / \mathrm{cm}^{3}\right)$, early summer $\left(\Delta N_{\text {tot }}=500 \# / \mathrm{cm}^{3}\right)$ and autumn $\left(\Delta N_{\text {tot }}=\right.$ $1500 \# / \mathrm{cm}^{3}$ ), but the yearly cycle is fairly well captured. REMO-HAM has a similar yearly cycle to the measurements, but the fluctuations in concentrations are higher. In some cases, the concentration peaks are higher than the measurement or results from ECHAM5-HAM, but overall REMO-HAM gives lower concentrations. In any case, the values from ECHAM5-HAM are fairly close to the measurements, whereas REMO-HAM has problems during late winter $\left(\Delta N_{\text {tot }}=3000 \# / \mathrm{cm}^{3}\right)$, late summer $\left(\Delta N_{\text {tot }}=\right.$ $\left.2000 \# / \mathrm{cm}^{3}\right)$ and autumn $\left(\Delta N_{\text {tot }}=2500 \# / \mathrm{cm}^{3}\right)$.

Although two boundary layer (BL) nucleation schemes are implemented in the models (Sect. 2.3), these schemes were turned off for these simulations. For testing purposes, we have done simulation with activation and kinetic BL nucleation, but the results showed severe overestimation in total particle numbers (results not shown). This suggests that the absence of a BL nucleation scheme has contributed to the underestimation of particle numbers at Hyytiälä during spring and autumn, which are typical nucleation event times at that site (Dal Maso et al., 2005). This has been also shown with different modeling studies. For example, Spracklen et al. (2010) and Reddington et al. (2011) showed that activation and kinetic BL nucleation does improve the modelled aerosol concentrations. Moreover, Spracklen et al. (2006) showed that either BL nucleation or primary emissions cannot directly explain the measured concentrations at Hyytiälä, but that the sum of these is the best fit to the measurements. This means that the models would give higher concentrations during spring, summer and autumn, which can be also seen from the study by Spracklen et al. (2010). The reason for the high nucleation rates with both of the BL nucleation 

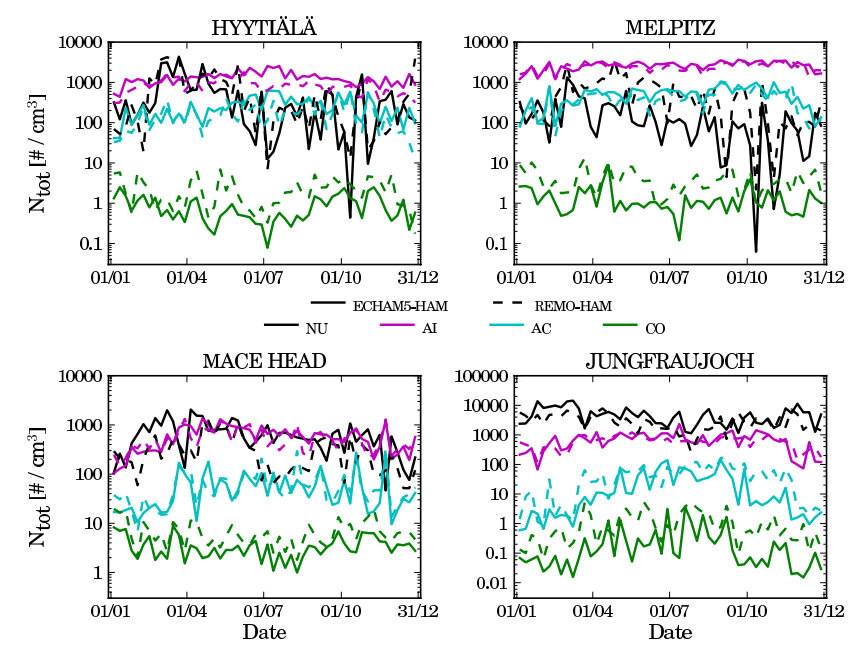

Fig. 3. The weekly mean number concentrations for nucleation (NU), Aitken (AI), accumulation (AC) and coarse (CO) mode. The values from ECHAM5-HAM are represented by the solid lines (-) and REMO-HAM (50 km resolution) by the dashed lines (- -).

schemes is the too high $\mathrm{SO}_{2}$ concentrations in the models (this is shown in Fig. 7). Overall, the values from ECHAM5HAM and REMO-HAM are similar as in Spracklen et al. (2010) and Reddington et al. (2011), although it must be said that in the latter study the simulated period is only one month long.

From Fig. 3 we can see that the modal number concentrations between the models do not differ much at Hyytiälä. The Aitken mode is smaller in REMO-HAM during the whole year, which can explain the differences in Fig. 2. For example, the large underestimate of $N_{\text {tot }}$ in REMO-HAM for the late winter comes from the Aitken mode. One possible explanation is the resolution of the models: based on our other simulations, ECHAM5-HAM spreads the emissions much wider than REMO-HAM. Also, if the resolution of emissions is too coarse (like in our case, coarser than the grid used in REMOHAM), local emission sources might not be positioned completely correctly. If we look at the nucleation mode, the concentrations are a bit higher in REMO-HAM, but the difference is not very big.

The results from Melpitz show that the models give lower concentration than the measurements throughout the whole year $\left(\Delta N_{\text {tot }}=1000-4000 \# / \mathrm{cm}^{3}\right)$ and that the difference between the models is quite small. Similar behavior and concentrations can also be seen in Reddington et al. (2011) and Spracklen et al. (2010). In the latter work, it was shown that for Melpitz, BL nucleation and/or increased carbon emissions could explain the underestimation. When looking at the two different REMO-HAM resolutions, the difference is barely discernible. Unlike at Hyytiälä, the nucleation mode concentrations differ the most. On the other hand, the Aitken mode concentrations are much higher and dominate the total number concentrations (Fig. 3). This is why the difference in
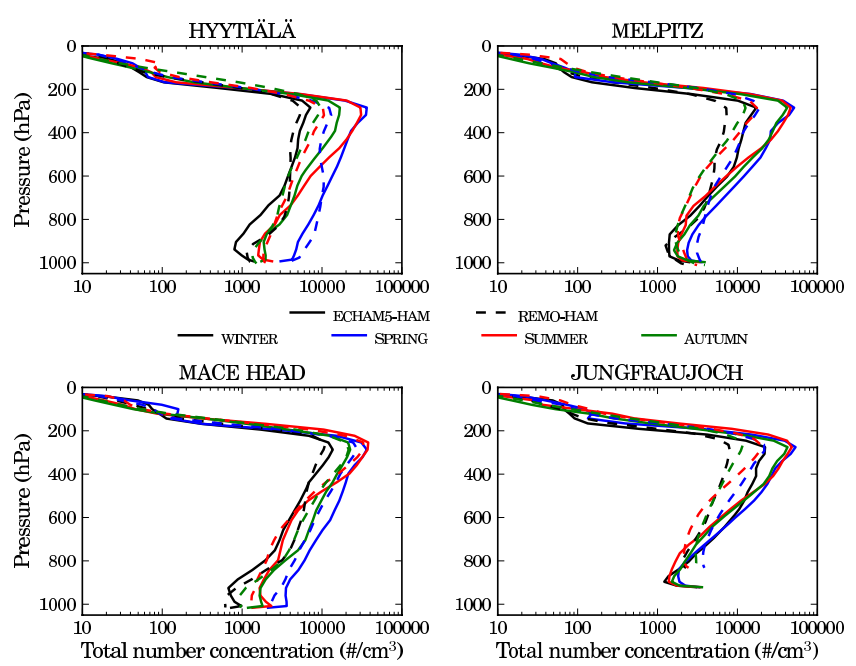

Fig. 4. The seasonal mean number concentrations as a function of pressure. The values from ECHAM5-HAM are represented by the solid lines (-) and REMO-HAM (50 km resolution) by the dashed lines (- -).

nucleation mode is not visible in the total number concentrations.

At Mace Head, ECHAM5-HAM reproduces the measured values fairly well during the first half of the year, but underestimates the concentrations during the second half $\left(\Delta N_{\text {tot }}=\right.$ $\left.1000 \# / \mathrm{cm}^{3}\right)$. REMO-HAM has the same pattern, although during late winter and spring time the concentrations are lower than in ECHAM5-HAM and measurements $\left(\Delta N_{\text {tot }}=\right.$ $\left.2500 \# / \mathrm{cm}^{3}\right)$. Once again, this same behavior and concentrations have been modelled before, and the BL nucleation can be the key factor (Reddington et al., 2011; Spracklen et al., 2010). Figure 3 shows that the difference between ECHAM5-HAM and REMO-HAM comes from the nucleation mode, which is lower in REMO-HAM during the first quarter of the year, and in summer and autumn. This result is in good agreement with the low total number concentration seen in Fig. 2.

As mentioned in Sect. 4, the Jungfraujoch measurement site is located in a mountainous region. These kind of areas are demanding for the model and the results have greater error than usual, which can be seen from Fig. 2. The concentrations given by the models are too high throughout the year. ECHAM5-HAM has somewhat higher concentrations $\left(\Delta N_{\text {tot }}=4000 \# / \mathrm{cm}^{3}\right)$ than REMO-HAM $\left(\Delta N_{\text {tot }}=\right.$ $\left.3000 \# / \mathrm{cm}^{3}\right)$. The $10 \mathrm{~km}$ resolution simulation has slightly higher concentrations, but the difference between the resolutions is not very significant $\left(\Delta N_{\text {tot }}=3500 \# / \mathrm{cm}^{3}\right)$. This is not the case with Reddington et al. (2011) and Spracklen et al. (2010), who both modelled much lower concentrations $\left(N_{\text {tot }} \approx 1000 \# / \mathrm{cm}^{3}\right)$. The difference between ECHAM5HAM and REMO-HAM $(50 \mathrm{~km})$ in nucleation mode can be seen from Fig. 3 and the interesting point is that the 

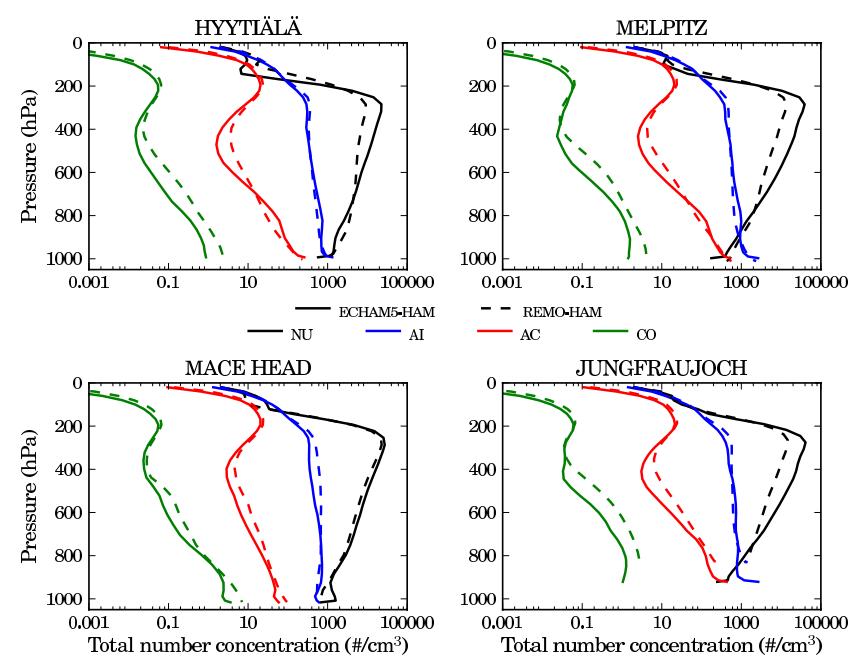

Fig. 5. The yearly mean number concentrations for different modes as a function of pressure: nucleation (NU), Aitken (AI), accumulation $(\mathrm{AC})$ and coarse $(\mathrm{CO})$ mode. The values from ECHAM5-HAM are represented by the solid lines (-) and REMO-HAM $(50 \mathrm{~km}$ resolution) by the dashed lines (- -).

nucleation mode concentrations are very high compared to other measurement sites. Later on in Fig. 4, it is shown that at higher altitudes the concentrations increase. This explains why the concentrations are so high at Jungfraujoch. The reason for the high concentration on higher altitudes is explained in Sect. 4.1.2.

Figures 2 and 3 show the number concentrations only from the lowest model layer, except for Jungfraujoch where the model level is matched to the measurement by pressure. In this work, we have not included vertical measurement data, but we compare ECHAM5-HAM and REMOHAM (50 km resolution) profiles. From Fig. 4 we see how the vertical distribution of particle number changes seasonally. ECHAM5-HAM has higher concentrations at all sites below $750 \mathrm{hPa}$. Above this, REMO-HAM has higher concentrations at Hyytiälä and Melpitz, excluding the highest pressure levels (close to the surface). Also noticeable is that total number concentrations get higher until around $300 \mathrm{hPa}$ and then start to decrease. This kind of behavior has been previously observed in ECHAM5-HAM by Kazil et al. (2010). The reason for this is the high concentration in the nucleation mode, which can be seen from Fig. 5 (note: these values are annual means which smooths out differences when compared to seasonal values). We can see how the nucleation mode dominates the total number concentrations from $200 \mathrm{hPa}$ to $900 \mathrm{hPa}$. REMO-HAM has somewhat higher concentrations in all of the modes (with some fluctuations), except the nucleation mode, which is higher in ECHAM5-HAM. At higher altitudes, the difference is no longer noticeable. Also interesting is the effect of coarser orography at Jungfraujoch with ECHAM5-HAM, which causes the pressure levels at
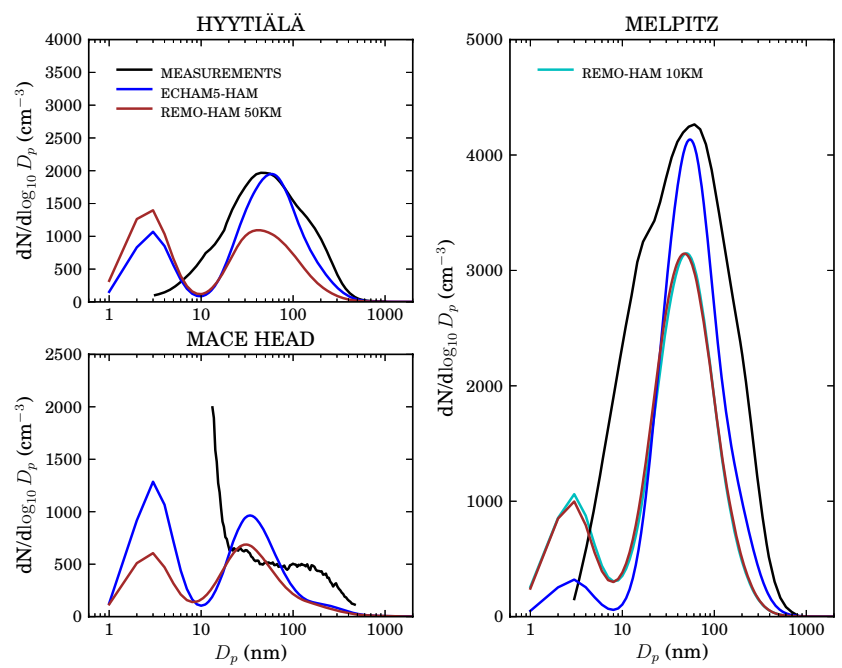

Fig. 6. The yearly mean aerosols size distributions from three measurements sites.

Jungfraujoch to be higher than in REMO-HAM (see Fig. 5). The low horizontal resolution tends to smoothen the orographical differences which is why REMO-HAM has a better representation of the Alps (the coarse and accumulation mode minima are at higher altitudes than with ECHAM5HAM). Figure 5 also shows why the nucleation mode concentration is so high at Jungfraujoch in Fig. 2. As mentioned, Jungfraujoch station is located at the Alps and the values in Fig. 2 were chosen based on the pressure levels (higher altitude). This leads to higher nucleation mode concentrations at Jungfraujoch station.

Kazil et al. (2010) showed that in ECHAM5-HAM, the increase in nucleation mode concentrations as a function of altitude is stronger than measurements indicate, at least in $\mathrm{Pa}$ cific regions. Possible reasons for this include too high $\mathrm{SO}_{2}$ concentrations which can lead to too high $\mathrm{H}_{2} \mathrm{SO}_{4}$ levels affecting the nucleation. Also, the oxidation processes may influence the $\mathrm{H}_{2} \mathrm{SO}_{4}$ budget and the treatment of ultrafine particles in M7 in terms of the mode limits can have an effect on the concentrations. In addition, Kazil et al. (2010) showed that the ultrafine particle number concentrations are high in ECHAM5-HAM regardless of the nucleation method used. In this work, we use the binary sulfuric acid - water based nucleation scheme, which favors colder temperatures. For the BL values, activation or kinetic nucleation would smooth out the difference due the higher concentrations on higher altitudes, which would of course be more important in the European boundary layer compared with Pacific areas.

\subsubsection{Aerosol size distributions}

As mentioned in the previous section, the nucleation mode can explain the difference in total number concentrations between the models at Melpitz, Mace Head and Jungfraujoch. 
The high concentrations in the nucleation mode can be also seen in Fig. 6, where the yearly mean size distributions from Hyytiälä, Melpitz and Mace Head as well as the modeled mean distributions are shown. Results from Hyytiälä show that the distributions from the models are quite similar to the measurements, except for small particles, which are overestimated. The width of the distribution is not quite captured, although ECHAM5-HAM has a wider distribution than with REMO-HAM. The peak is almost in the right place for both of the models and ECHAM5-HAM has the height of the main peak very well captured, whereas REMO-HAM underestimates the concentrations. At Mace Head, similar behavior can be seen, although both of the models underestimate the concentration of the larger particles. The noticeable difference is that ECHAM5-HAM has more particles in the smallest sizes, which is in agreement with the spring and summer time higher nucleation mode concentrations as seen in Fig. 3. At Melpitz, we can see features similar to the other sites, but the form of the distributions gives some clue as to why the models differ. It seems that in the case of ECHAM5-HAM, more gas phase sulfuric acid condenses on the particles and this leads to smaller nucleation mode and to the higher and wider distribution. In the next section we will explain this in more detail.

\subsubsection{Nucleation mode and gas phase}

In this work, neither the activation nor the kinetic nucleation schemes were used. However, the neutral and charged $\mathrm{H}_{2} \mathrm{SO}_{4} / \mathrm{H}_{2} \mathrm{O}$ nucleation scheme by Kazil and Lovejoy (2007) was used in both of the models during the simulation period. In this approach, the nucleation rate depends on the sulfuric acid concentration. The source for gas phase sulfate is the oxidation processes of $\mathrm{SO}_{2}$ and DMS, as described in Sect. 2.3. The concentrations of $\mathrm{SO}_{2}$ (especially in continental areas) are much higher than those of DMS, and thus it is the main proxy for gas phase sulfate production (Hamed et al., 2010). The difference in the nucleation mode between ECHAM5-HAM and REMO-HAM could be explained by higher nucleation rates, which would be the results of higher sulfate (sulfuric acid) concentrations due to the different $\mathrm{SO}_{2}$ concentrations.

Figure 7 shows the $\mathrm{SO}_{2}$ gas phase concentrations for all the measurement sites and models (here the results from Valentia, Ireland, instead of Mace Head are shown). It is quite clear that both of the models overestimate $\mathrm{SO}_{2}$ concentrations at all of the measurement sites. At Hyytiälä, REMOHAM has higher values than measurements, especially during winter and early spring. ECHAM5-HAM has similar values for the beginning of the year, although in a few cases slightly lower than those in REMO-HAM. Later on, values in REMO-HAM decrease, but are still higher than the measurements. ECHAM5-HAM also has a decreasing slope, but the values start to increase during the summer and are too high especially during the late autumn and winter. At Melpitz, the
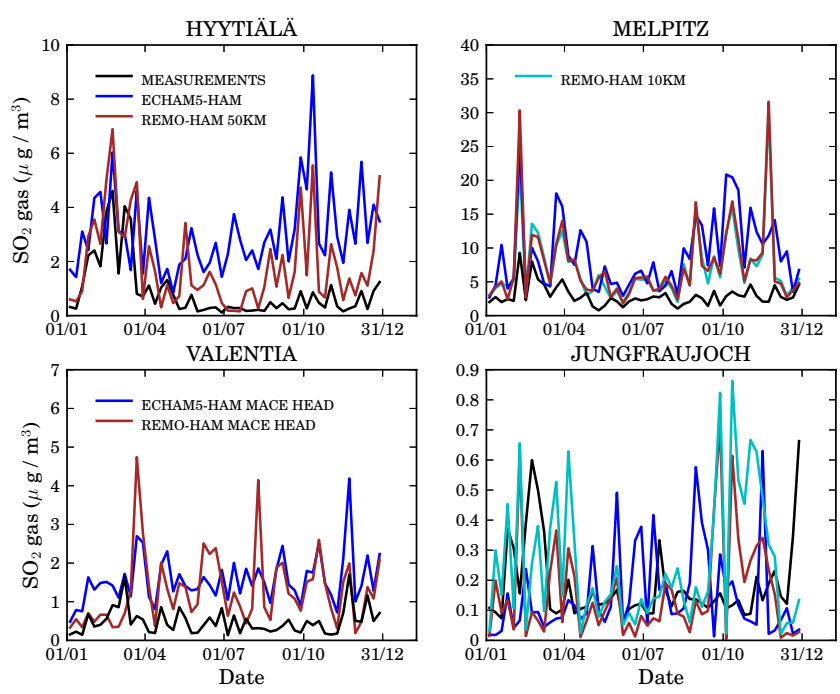

Fig. 7. The weekly mean $\mathrm{SO}_{2}$ gas phase concentration from different measurement sites as a function of time. For Mace Head, the measured values from Valentia are shown.

values are quite high in both of the models. The total number concentrations are underestimated at Melpitz and the reason for this is the low concentration in the nucleation mode. Although $\mathrm{SO}_{2}$ concentrations are high at Melpitz, the nucleation mode number concentration is not, because there is not enough sulfuric acid to activate nucleation. The reason for this is the Aitken mode. As we can see from Fig. 3, the Aitken mode concentration is quite high at Melpitz. This leads to a larger condensation sink, which in turn leads to low sulfuric acid concentrations. This can be also seen from Fig. 6, where the nucleation peaks are low at Melpitz, but otherwise the distribution is high and wide. In case of REMO-HAM, the condensation sink is lower and there is more sulfuric acid to activate nucleation. This can be seen from Figs. 3 and 6 . The reason for differences in the Aitken mode are most probably due to resolution, which affects aerosol transport of species (emissions spread wider with coarse resolution). Another factor can be the coarse resolution of emission. Some local important emission sources can be mislocated (in terms of grid boxes) when the emissions are remapped from the coarse resolution to the higher resolution.

As previously mentioned, the model versions used included some changes to dry deposition, which decrease the $\mathrm{SO}_{2}$ concentrations. If we look more closely at how the nucleated particles grow in $\mathrm{M} 7$, the only condensing substance (besides water) is sulfuric acid. It seems that when the $\mathrm{SO}_{2}$ concentrations decrease, the sulfuric acid concentrations decrease as well and the condensation is no longer high enough to grow the particles. This can be seen from Fig. 6, where the nucleation mode has high peaks on every measurement site.

The activation and kinetic boundary layer nucleation schemes were not used in this work, because the sulfuric acid concentrations were so high. The implemented $\mathrm{BL}$ 

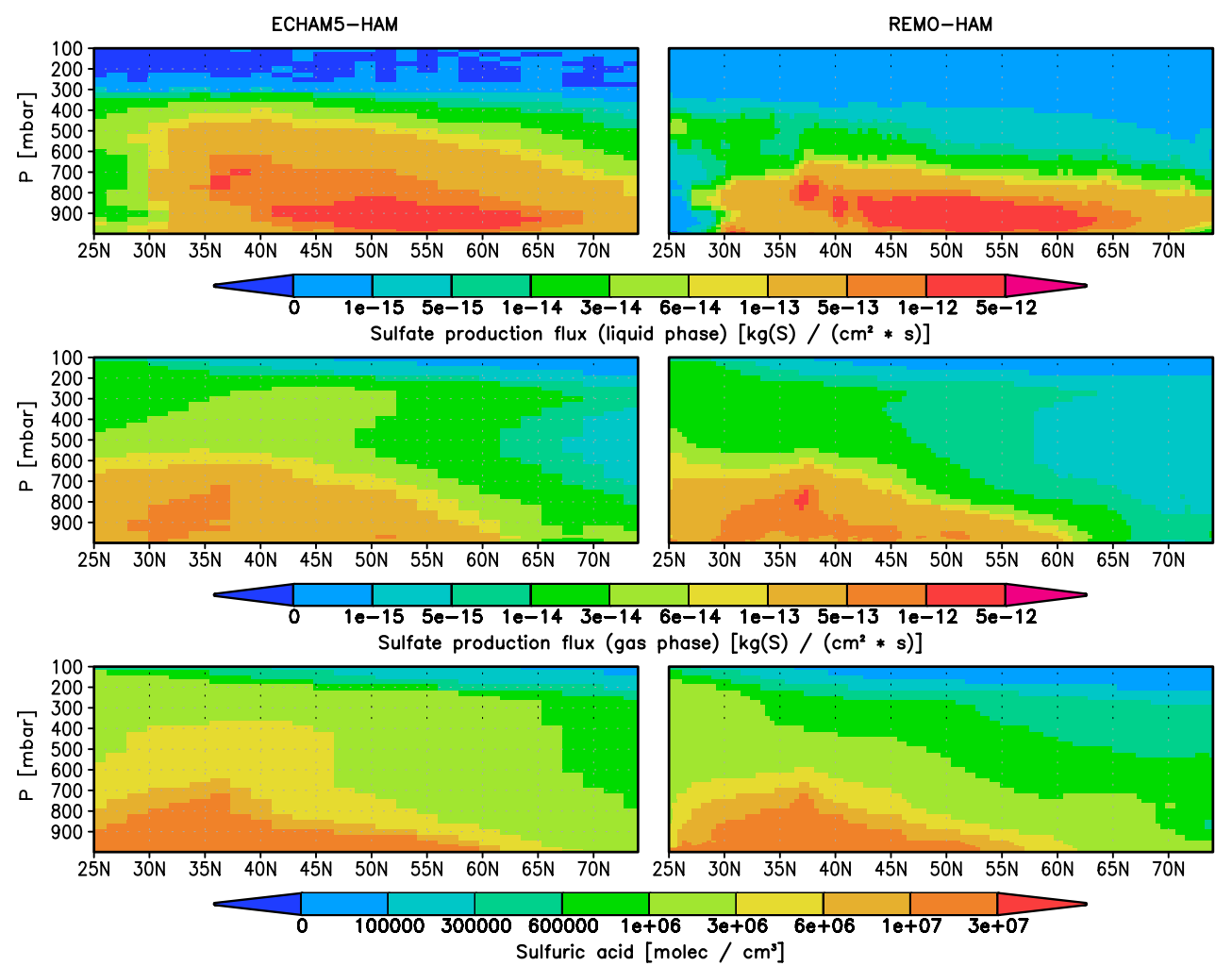

Fig. 8. Zonal mean sulfate production fluxes (upper panel for liquid phase and central for gas phase) and zonal mean sulfuric acid concentrations (lower panel) for the year 2005: ECHAM5-HAM on the left column and REMO-HAM on the right column.

nucleation schemes are very sensitive to $\mathrm{H}_{2} \mathrm{SO}_{4}$ concentration and without condensation of organic matter (SOA model), the nucleation mode concentrations would be unrealistically high. We are currently working on the problem of too high $\mathrm{SO}_{2}$ and $\mathrm{H}_{2} \mathrm{SO}_{4}$ concentrations in other projects. For example, the chemistry part of the models is being improved in terms of the oxidant fields.

Figure 8 shows the zonal and yearly means for Europe for sulfate production rates and sulfuric acid concentrations for both of the models. Liquid phase production comes from the oxidation of $\mathrm{SO}_{2}$ by $\mathrm{H}_{2} \mathrm{O}_{2}$ and $\mathrm{O}_{3}$, and gas phase production from the oxidation of DMS by $\mathrm{OH}$ and $\mathrm{SO}_{2}$ by $\mathrm{OH}$. We see that the production rates are fairly similar in the liquid and gas phases. The biggest difference is that in ECHAM5HAM, the production rates are higher at higher altitudes. This is connected to the $\mathrm{SO}_{2}$ concentrations, which are also higher in ECHAM5-HAM. On the other hand, the low liquid phase production rates over the Sahara in REMO-HAM are a direct effect of lower cloudiness (and precipitation). The precipitation bias can be seen (later on) from Fig. 11. The sulfuric acid $\left(\mathrm{H}_{2} \mathrm{SO}_{4}\right)$ concentrations are somewhat lower in REMO-HAM, but the pattern is similar to ECHAM5HAM. In any case, based on Fig. 8, we can state that the main processes in REMO-HAM for $\mathrm{H}_{2} \mathrm{SO}_{4}$ are working as they should. Small differences, such as those seen in the nucleation mode concentration in Fig. 3, can be explained by normal fluctuations arising from the different model resolutions.

\subsubsection{Spatial variability}

We can see from Fig. 9 how the different resolution of the models changes the spatial distribution of the total number concentration. The values shown are the mean values over summer months (June, July and August) and for lowest model layer. The difference in details between ECHAM5HAM and REMO-HAM $(50 \mathrm{~km})$ is considerable, although the main features of spatial distribution can be seen from both. The values are fairly similar for different areas, which was also shown in Fig. 2. If the two different REMO-HAM resolutions are compared, the difference is quite small. Some of the very local concentration peaks are different, but the main features of the spatial distribution are more or less identical. This is because of two main reasons: firstly, the higher resolution was driven by the lower resolution simulation and secondly, the emissions database was the same for both of the simulations and it had coarser resolution than either of the model versions. It is quite clear that if we want to use the full benefit of the high resolution, the emission database needs to be updated, at least in terms of the spatial resolution. The resolution difference between the AEROCOM emissions 


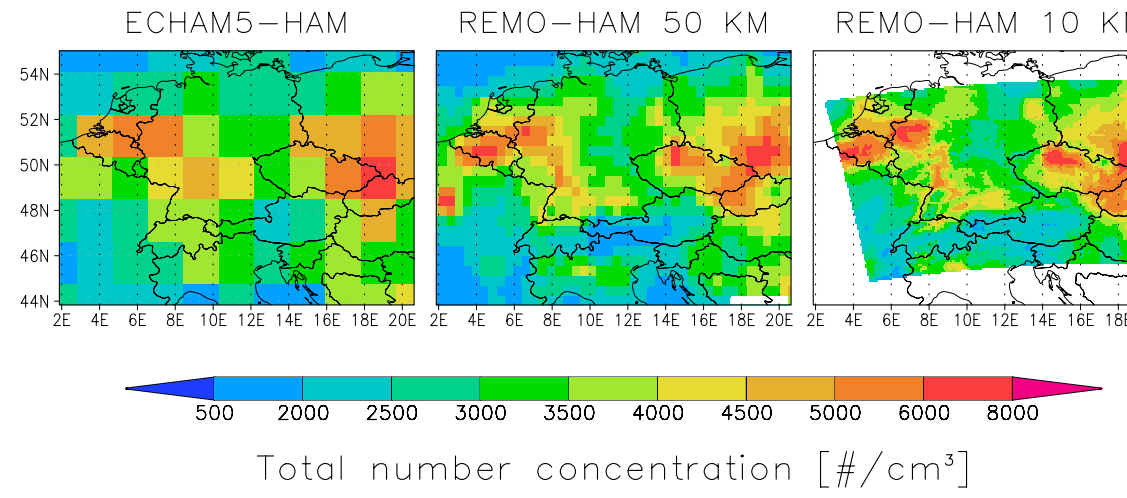

Fig. 9. The mean aerosol total number concentration for the different models. Only the values from the lowest model layer are shown and the values are means over the summer months (June, July and August).
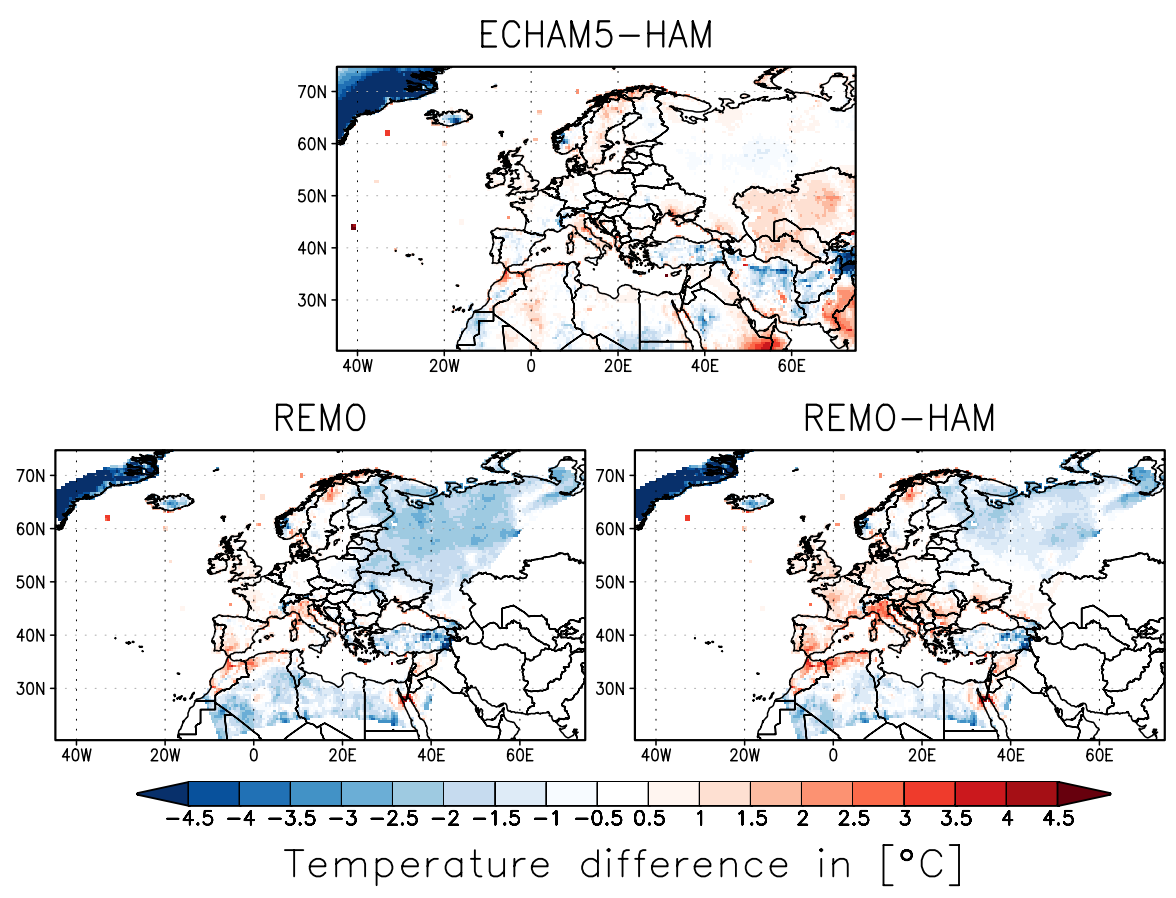

Fig. 10. Temperature difference (model-measurements) for ECHAM5-HAM, REMO and REMO-HAM.

and the $10 \mathrm{~km}$ simulation is too high. A higher resolution database should be used, otherwise the coarse emissions will smoothen out the benefits of accurate grid. It should also be mentioned that higher resolution in time has the potential to bring further differences between different model resolutions (now most of the species use monthly fields). In any case, Fig. 9 shows how much the higher resolution of regional aerosol-climate model can improve the spatial representation of the aerosol concentrations, and how sensitive the models are for the resolution of the emissions.

\subsection{Meteorological variables}

We have compared the meteorological model results with the Climatic Research Unit data (University of East Anglia Climatic Research Unit, 2008). The data used is the CRU TS 3.0 global dataset with $0.5^{\circ}$ resolution. The dataset only has measurement data over land so all sea areas are excluded. The comparison with the dataset is done for the precipitation and temperature from ECHAM5-HAM, REMO and REMOHAM. The model data is remapped to the CRU grid. Using a conservative remapping for precipitation fields and bilinear remapping for temperature fields the data is matched with the measurement grid. The temperature fields are also 

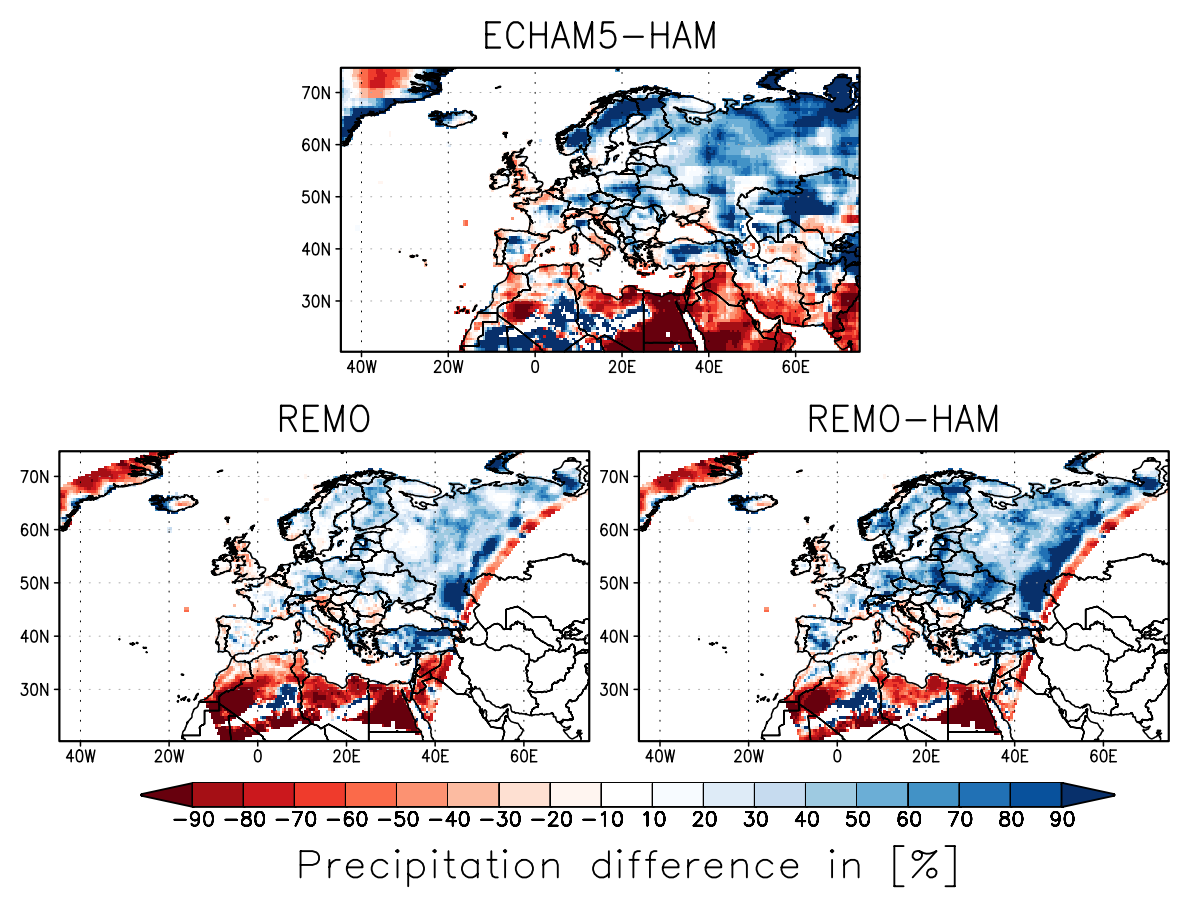

Fig. 11. Precipitation difference ((model-measurements)/measurements*100\%) for ECHAM5-HAM, REMO and REMO-HAM.

adjusted according to different orographies between CRU and the models. The lapse rate $\gamma=0.0064{ }^{\circ} \mathrm{C} \mathrm{m}^{-1}$ is used to compensate the orography difference in temperatures. The remapping is done for the ECHAM5-HAM global T63 grid and REMO $0.44^{\circ}$ grid.

Figure 10 shows the temperature difference (modelmeasurements) for each of the models. We can see that ECHAM5-HAM is quite close to the measurements throughout Europe. This is of course an expected result since the ECHAM5-HAM simulation was nudged. On the other hand, the REMO and REMO-HAM simulations were not nudged (they were only driven by the ECMWF analysis data at the lateral boundaries) and, as we can see, both models reproduce the measured values fairly well. REMO has a small cold bias over Eastern Europe, whereas in REMO-HAM this is hardly perceptible. Both models have a warm bias over Western Europe, especially REMO-HAM. The main reason for the higher 2-m temperature in REMO-HAM is a larger sensible heat flux due to higher down-welling short-wave radiation. A reduced cloud cover in REMO-HAM due to more precipitation increases the short-wave radiation at the surface, causing higher skin and near-surface temperatures. We will further analyze the feedback effects in future publications. Moreover, some of the areas with high bias are located in polluted areas and a radiation scheme including HAM aerosol information would be a valuable addition to the model. The direct effect of aerosols can play an important role, especially on regional scales (Zubler et al., 2011b).
Figure 11 shows the precipitation difference ((modelmeasurements)/measurements) for each of the models. ECHAM5-HAM seems to have a wet bias over Eastern and Central Europe, and a dry bias over some parts of Western Europe, North Africa and the Middle East. REMO and REMO-HAM have the same pattern, but the biases are not as high as with ECHAM5-HAM. REMO is overall closer to the measurements than REMO-HAM, which has a wet bias, especially over Eastern Europe. The pattern of precipitation between the models is quite similar. REMO and REMO-HAM have systematic precipitation differences along the boundaries, which is an effect of the relaxation scheme (prognostic variables are adjusted within eight outermost grid boxes). The large-scale driving field influence decreases exponentially from the outermost boundary towards the center of the domain.

REMO-HAM currently uses the same autoconversion parameters as used in ECHAM5-HAM with a resolution scaling factor. These scaling factors change the autoconversion parameters according to the resolution and have an impact on the precipitation. The effect of the scaling parameters should be studied further; this work is ongoing.

\section{Conclusions}

We have performed simulations with the regional aerosolclimate regional model REMO-HAM with two different horizontal resolutions: $50 \times 50 \mathrm{~km}^{2}$ and $10 \times 10 \mathrm{~km}^{2}$. In addition, we carried out simulations with the global aerosol-climate 
model ECHAM5-HAM. The simulations were for the year 2005 after a sufficiently long spin-up time. The aerosol related tracer data from the ECHAM5-HAM simulation were used as lateral boundary data for REMO-HAM. ECHAM5HAM was nudged with ECMWF operational analysis data and REMO-HAM used the same data at the lateral boundaries of the model domain.

The results from both of the models were compared against aerosol measurements from four different measurement sites. We have shown that the REMO-HAM can represent the measured aerosol concentrations and size distributions fairly realistically. Overall the concentrations are somewhat low, but one has to keep in mind that this version of REMO-HAM does not include an online SOA-model, and that neither the activation nor kinetic nucleation scheme for the boundary layer were used. With ECHAM5-HAM, the total number concentrations shows similar patterns as REMOHAM. The difference between the models can be mainly explained by the nucleation mode, which differs in time and space. The nucleation mode is linked to the sulfur dioxide concentrations through oxidation and nucleation. We have shown that the models tend to overestimate the sulfur dioxide concentrations and this leads to high nucleation rates. In some cases, like at Melpitz, the background concentration of aerosol was high enough to increase the condensation of sulfuric acid to particles and this led to lower nucleation rates. We implemented some improvements to the models in terms of dry deposition. These improvements led to lower sulfur dioxide and sulfuric acid levels, but raised a new problem: the condensation of sulfuric acid is no longer high enough to grow the smaller particles to larger sizes. One thing missing in REMO-HAM is the growth of particles by organic matter. ECHAM5-HAM has a secondary organic aerosol version (O'Donnell et al., 2011), but it was not used in this study. Since the aerosol module structure is similar in both of the models, we will study the option of implementing the SOA model by O'Donnell et al. (2011) into REMO-HAM.

Emissions are the dominant factor for number concentrations in the lowest model layers. In this study, we tested REMO-HAM with two different horizontal resolutions $\left(0.44^{\circ}\right.$ and $\left.0.088^{\circ}\right)$. Differences in the aerosol concentrations are small between the two REMO-HAM simulations, as both use the same emission fields. This means that although REMO-HAM with $0.088^{\circ}$ resolution is able to solve the circulation with much higher accuracy, the coarse emissions were a restricting factor for the aerosol concentrations. In order to use high resolution aerosol-climate models for detailed studies, a high resolution emissions dataset should be used.

Temperature and precipitation fields from REMO-HAM were evaluated by comparing the parameters to CRU observations. REMO-HAM captures the annual mean temperature reasonably well, but overestimates the precipitation amount in most regions. The meteorology of the model will be studied more thoroughly in forthcoming publications (for example, the effect of scaling parameter to the autoconversion parameters). Moreover, the difference in sulfur species will be studied in more detail in the future.

Acknowledgements. We wish to thank Sebastian Rast (MPI-M Hamburg) for all the help with $\operatorname{ECHAM(5-HAM)~model.~We~are~}$ also grateful to Margaret Ryan (Met Éireann, Ireland) for providing the Valentia observatory data. Many thanks also to Ulrike Lohmann (ETH Zürich) for all the help with the new cloud scheme. We would also like to acknowledge the support from the Academy of Finland (project nr. 136175), Emil Aaltonen Foundation, Saastamoinen Foundation, and the University of Eastern Finland.

Edited by: A. Kerkweg

\section{References}

Abdul-Razzak, H and Razzak, S. J.: A parameterization of aerosol activation 2. Multiple aerosol types, J. Geophys. Res., 105, 68376844, 2000.

Bashir, W., Ryan, M., Burke, L., McGovern, F., and Paull, B.: An analysis of the ionic composition of Irish precipitation and background air quality since 1980 based on samples collected at Valentia Observatory, Co. Kerry, Ireland, Air Pollution XIV, 545-555, 2006.

Beheng K. D.: A parametrization of warm cloud microphysical conversion processes, Atmos. Res., 33, 193-206, 1994.

Birmili, W. and Wiedensohler, A.: New particle formation in the continental boundary layer: Meteorological and gas phase parameter influence, Geophys. Res. Lett., 27, 3325-3328, 2000.

Collaud Coen, M., Weingartner, E., Nyeki, S., Cozic, J., Henning, S., Verheggen, B., Gehrig, R., and Baltensperger, U.: Long-term trend analysis of aerosol variables at the highalpin site Jungfraujoch, J. Geophys. Res., 112, D13213, doi:10.1029/2006JD007995, 2007.

Collaud Coen, M., Weingartner, E., Furger, M., Nyeki, S., Prévôt, A. S. H., Steinbacher, M., and Baltensperger, U.: Aerosol climatology and planetary boundary influence at the Jungfraujoch analyzed by synoptic weather types, Atmos. Chem. Phys., 11, 5931-5944, doi:10.5194/acp-11-5931-2011, 2011.

Croft, B., Lohmann, U., Martin, R. V., Stier, P., Wurzler, S., Feichter, J., Posselt, R., and Ferrachat, S.: Aerosol size-dependent below-cloud scavenging by rain and snow in the ECHAM5HAM, Atmos. Chem. Phys., 9, 4653-4675, doi:10.5194/acp-94653-2009, 2009.

Dal Maso, M., Kulmala, M., Riipinen, I., Wagner, R., Hussein, T., Aalto, P. P., and Lehtinen, K. E. J.: Formation and growth of fresh atmospheric aerosols: eight years of aerosol size distribution data from SMEAR II, Hyytiala, Finland, Boreal Env. Res.,, 10, $323-$ 336, 2005.

Davies, H. C.: A lateral boundary formulation for multi-level prediction models, Q. J. Roy. Meteorol. Soc., 102, 405-418, 1976.

Dentener, F., Kinne, S., Bond, T., Boucher, O., Cofala, J., Generoso, S., Ginoux, P., Gong, S., Hoelzemann, J. J., Ito, A., Marelli, L., Penner, J. E., Putaud, J.-P., Textor, C., Schulz, M., van der Werf, G. R., and Wilson, J.: Emissions of primary aerosol and precursor gases in the years 2000 and 1750 prescribed data-sets for Ae- 
roCom, Atmos. Chem. Phys., 6, 4321-4344, doi:10.5194/acp-64321-2006, 2006.

Feichter, J., Kjellström, E., Rodhe, H., Dentener, F., Lelieveld, J., and Roelofs, G.-J.: Simulation of the tropospheric sulfur cycle in a global climate model, Atmos. Environ., 30, 1693-1707, 1996.

Ganzeveld, L. and Lelieveld, J.: Dry deposition parameterization in a chemistry general circulation model and its influence on the distribution of reactive trace gases, J. Geophys. Res., 100, 20999-21012, 1995.

Ganzeveld, L., Lelieveld, J., and Roelofs, G.-J.: A dry deposition parameterization for sulfur oxides in a chemistry and general circulation model, J. Geophys. Res., 103, 5679-5694, 1998.

Hamed, A., Birmili, W., Joutsensaari, J., Mikkonen, S., Asmi, A., Wehner, B., Spindler, G., Jaatinen, A., Wiedensohler, A., Korhonen, H., Lehtinen, K. E. J., and Laaksonen, A.: Changes in the production rate of secondary aerosol particles in Central Europe in view of decreasing $\mathrm{SO}_{2}$ emissions between 1996 and 2006, Atmos. Chem. Phys., 10, 1071-1091, doi:10.5194/acp-10-10712010, 2010.

Hansen, J., Sato, M., and Ruedy, R.: Radiative forcing and climate response. J. Geophys. Res., 102, 6831-6864, 1997.

Haywood, J. M. and Boucher, O.: Estimates of the direct and indirect radiative forcing due to tropospheric aerosols: A review, Rev. Geophys., 38, 513-543, 2000.

Horowitz, L. W., Walters, S., Mauzerall, D. L., Emmons, L. K., Rasch, P. J., Granier, C., Tie, X., Lamarque, J.-F., Schultz, M. G., Tyndall, G. S., Orlando, J. J., and Brasseur, G. P.: A global simulation of tropospheric ozone and related tracers: Description and evaluation of MOZART, version 22, J. Geophys. Res., 108, 4784, doi:10.1029/2002JD002853, 2003.

IPCC, Intergovernmental Panel on Climate Change: Climate Change 2007: Synthesis Report, Cambridge Univ. Press, 2007.

Jacob, D.: A note to the simulation of the annual and inter-annual variability of the water budget over the Baltic Sea drainage basin, Meteorol. Amtos. Phys., 77, 61-73, 2001.

Jacob, D. and Podzun, R.: Sensitivity Studies with the Regonal Climate Model REMO, Meteorol. Amtos. Phys., 63, 119-129, 1996.

Jacobson, M. Z., Tabazadeh, A., and Turco, R. P.: Simulating equilibrium within aerosols and nonequilibrium between gases and aerosols, J. Geophys. Res., 101, 9079-9091, 1996.

Jones, A., Roberts, D. L., and Slingo, A.: A climate model study of indirect radiative forcing by anthropogenic sulphate aerosols, Nature, 370, 450-453, 1994.

Kazil, J. and Lovejoy, E. R.: A semi-analytical method for calculating rates of new sulfate aerosol formation from the gas phase, Atmos. Chem. Phys., 7, 3447-3459, doi:10.5194/acp-7-3447-2007, 2007.

Kazil, J., Stier, P., Zhang, K., Quaas, J., Kinne, S., O’Donnell, D., Rast, S., Esch, M., Ferrachat, S., Lohmann, U., and Feichter, J.: Aerosol nucleation and its role for clouds and Earth's radiative forcing in the aerosol-climate model ECHAM5-HAM, Atmos. Chem. Phys., 10, 10733-10752, doi:10.5194/acp-1010733-2010, 2010.

Khairoutdinov, M. and Kogan, Y.: A new cloud physics parameterization in a large-eddy simulation model of marine stratocumulus, Mon. Weather Rev., 128, 229-243, 2000.

Kokkola, H., Korhonen, H., Lehtinen, K. E. J., Makkonen, R., Asmi, A., Järvenoja, S., Anttila, T., Partanen, A.-I., Kulmala, M., Järvinen, H., Laaksonen, A., and Kerminen, V.-M.: SALSA
- a Sectional Aerosol module for Large Scale Applications, Atmos. Chem. Phys., 8, 2469-2483, doi:10.5194/acp-8-2469-2008, 2008.

Kokkola, H., Hommel, R., Kazil, J., Niemeier, U., Partanen, A.-I., Feichter, J., and Timmreck, C.: Aerosol microphysics modules in the framework of the ECHAM5 climate model - intercomparison under stratospheric conditions, Geosci. Model Dev., 2, 97-112, doi:10.5194/gmd-2-97-2009, 2009.

Kulmala, M., Vehkamäki, H., Petäjä, T., Dal Maso, M., Lauri, A., Kerminen, V.-M., Birmili, W., and McMurry, P. H.: Formation and growth rates of ultrafine atmospheric particles: A review of observations, J. Aerosol. Sci., 35, 143-176, 2004.

Kulmala, M., Lehtinen, K. E. J., and Laaksonen, A.: Cluster activation theory as an explanation of the linear dependence between formation rate of $3 \mathrm{~nm}$ particles and sulphuric acid concentration, Atmos. Chem. Phys., 6, 787-793, doi:10.5194/acp-6-787-2006, 2006.

Laakso, L., Anttila, T., Lehtinen, K. E. J., Aalto, P. P., Kulmala, M., Hõrrak, U., Paatero, J., Hanke, M., and Arnold, F.: Kinetic nucleation and ions in boreal forest particle formation events, Atmos. Chem. Phys., 4, 2353-2366, doi:10.5194/acp-4-2353-2004, 2004.

Laaksonen, A., Hamed, A., Joutsensaari, J., Hiltunen, L., Cavalli, F., Junkermann, W., Asmi, A., Fuzzi, S., and Facchini, M. C.: Cloud condensation nucleus production from nucleation events at a highly polluted region. Geophys. Res. Lett., 32, L06812, doi:10.1088/1748-9326/3/4/045022, 2005.

Langmann, B.: Numerical modelling of regional scale transport and photochemistry directly together with meteorological processes, Atmos. Environ., 34, 3585-3598, 2000.

Langmann, B., Varghese, S., Marmer, E., Vignati, E., Wilson, J., Stier, P., and O'Dowd, C.: Aerosol distribution over Europe: a model evaluation study with detailed aerosol microphysics, Atmos. Chem. Phys., 8, 1591-1607, doi:10.5194/acp-8-1591-2008, 2008.

Lin, H. and Leaitch, W. R.: Development of an in-cloud aerosol activation parameterization for climate modelling, in: Proceedings of the WMO Workshop pn Measurement of Cloud Properties for Forecast of Weather, Air Quality and Climate, World Meteorol. Organ., Geneva, 328-335, 1997.

Lohmann, U. and Feichter, J.: Global indirect aerosol effects: a review, Atmos. Chem. Phys., 5, 715-737, doi:10.5194/acp-5-7152005, 2005.

Lohmann, U. and Kärcher, B.: First interactive simulations of cirrus clouds formed by homogeneous freezing in the ECHAM general circulation model, J. Geophys. Res., 107, 4105, doi:10.1029/2001JD000767, 2002.

Lohmann, U. and Roeckner, E.: Design and performance of a new cloud microphysics scheme developed for the ECHAM genereal circulation model, Clim. Dynam., 12, 557-572, 1996.

Lohmann, U., Stier, P., Hoose, C., Ferrachat, S., Kloster, S., Roeckner, E., and Zhang, J.: Cloud microphysics and aerosol indirect effects in the global climate model ECHAM5-HAM, Atmos. Chem. Phys., 7, 3425-3446, doi:10.5194/acp-7-3425-2007, 2007.

Lohmann, U., Spichtinger, P., Jess, S., Peter, T. and Smit, H.: Cirrus cloud formation and ice supersaturated regions in a global climate model, Environ. Res. Lett., 3, 045022, doi:10.1088/17489326/3/4/045022, 2008. 
Louis, J.-F.: A parametric model of vertical eddy fluxes in the atmosphere, Bound.-Lay. Meteorol. 17, 187-202, 1979.

Makkonen, R., Asmi, A., Korhonen, H., Kokkola, H., Järvenoja, S., Räisänen, P., Lehtinen, K. E. J., Laaksonen, A., Kerminen, V.M., Järvinen, H., Lohmann, U., Bennartz, R., Feichter, J., and Kulmala, M.: Sensitivity of aerosol concentrations and cloud properties to nucleation and secondary organic distribution in ECHAM5-HAM global circulation model, Atmos. Chem. Phys., 9, 1747-1766, doi:10.5194/acp-9-1747-2009, 2009.

Mellor, B. and Yamada, T.: A hierarchy of turbulence closure models for planetary boundary layers, J. Atmos. Sci., 31, 1791-1806, 1974.

Nordeng, T. E.: Extended versions of the convective parametrization scheme at ECMWF and their impact on the mean and transient activity of the model in Tropics, ECMWF Tech. Memo., 206, available from ECMWF, Shineld Park, Reading, RG2 9AX, United Kingdom, 1994.

O'Connor, T. C., Jennings, S. G. and O'Dowd, C. D.: Highlights of fifty years of atmospheric aerosol research at Mace Head, Atmos. Res., 90, 338-355, 2008.

O'Donnell, D., Tsigaridis, K., and Feichter, J.: Estimating the direct and indirect effects of secondary organic aerosols using ECHAM5-HAM, Atmos. Chem. Phys., 11, 8635-8659, doi:10.5194/acp-11-8635-2011, 2011.

Petters, M. D. and Kreidenweis, S. M.: A single parameter representation of hygroscopic growth and cloud condensation nucleus activity, Atmos. Chem. Phys., 7, 1961-1971, doi:10.5194/acp-71961-2007, 2007.

Pierce, J. R. and Adams, P. J.: Uncertainty in global CCN concentrations from uncertain aerosol nucleation and primary emission rates, Atmos. Chem. Phys., 9, 1339-1356, doi:10.5194/acp-91339-2009, 2009.

Pfeifer, S.: Modeling cold cloud processes with the regional climate model REMO, PhD. Thesis, Reports on Earth System Science, Max Planc Institute for Meteorology, Hamburg, 2006.

Pleim, J. E., Chang, J. S. and Zhang, K. S.: A nested grid mesoscale atmospheric chemistry model, J. Geophys. Res., 96, 3065-3084, 1991.

Raatikainen, T., Vaattovaara, P., Tiitta, P., Miettinen, P., Rautiainen, J., Ehn, M., Kulmala, M., Laaksonen, A., and Worsnop, D. R.: Physicochemical properties and origin of organic groups detected in boreal forest using an aerosol mass spectrometer, Atmos. Chem. Phys., 10, 2063-2077, doi:10.5194/acp-10-20632010, 2010.

Reddington, C. L., Carslaw, K. S., Spracklen, D. V., Frontoso, M. G., Collins, L., Merikanto, J., Minikin, A., Hamburger, T., Coe, H., Kulmala, M., Aalto, P., Flentje, H., Plass-Dülmer, C., Birmili, W., Wiedensohler, A., Wehner, B., Tuch, T., Sonntag, A., O’Dowd, C. D., Jennings, S. G., Dupuy, R., Baltensperger, U., Weingartner, E., Hansson, H.-C., Tunved, P., Laj, P., Sellegri, K., Boulon, J., Putaud, J.-P., Gruening, C., Swietlicki, E., Roldin, P., Henzing, J. S., Moerman, M., Mihalopoulos, N., Kouvarakis, G., Ždímal, V., Zíková, N., Marinoni, A., Bonasoni, P., and Duchi, R.: Primary versus secondary contributions to particle number concentrations in the European boundary layer, Atmos. Chem. Phys., 11, 12007-12036, doi:10.5194/acp-11-12007-2011, 2011.

Roeckner, E., Arpe, K., Bengtsson, L., Christoph, M., Claussen, M., Dumenil, L., Esch, M., Schlese, U., and Schulzweida, U.: The atmospheric general circulation model ECHAM4: Model descrip- tion and simulation of present-day climate, Max Planck Institute for Meteorology report series, Report No. 218, 1996.

Roeckner, E., Baeuml, G., Bonventura, L., Brokopf, R., Esch, M., Giorgetta, M., Hagemann, S., Kirchner, I., Kornblueh, L., Manzini, E., Rhodin, A., Schlese, U., Schulzweida, U., and Tompkins, A.: The atmospheric general circulation model ECHAM5. PART I: Model description, Max Planck Institute for Meteorology report series, Report No. 349, 2003.

Seinfeld, J. and Pandis, S.: Atmospheric Chemistry and Physics, John Wiley \& Sons inc., 1998.

Smolarkiewicz, P. K.: Simple positive definite advection scheme with small implicit diffusion, Mon. Weather Rev., 111, 479486.1, 1983.

Smolarkiewicz, P. K.: A fully multidimensional positive definite advection transport algorithm with small implicit diffusion, J. Comput. Phys., 54, 325-362.1, 1984.

Sogacheva, L., Dal Maso, M., Kerminen., V.-M., and Kulmala, M.: Probability of nucleation events and estimation of aerosol particle sources at Hyytiälä, Southern Finland, using back trajectories, Boreal Env. Res., 10, 479-491, 2005.

Sogacheva, L., Hamed, A., Facchini, M. C., Kulmala, M., and Laaksonen, A.: Relation of air mass history to nucleation events in Po Valley, Italy, using back trajectories analysis, Atmos. Chem. Phys., 7, 839-853, doi:10.5194/acp-7-839-2007, 2007.

Spracklen, D. V., Carslaw, K. S., Kulmala, M., Kerminen, V.-M., Mann, G. W., and Sihto, S.-L.: The contribution of boundary layer nucleation events to total particle concentrations on regional and global scales, Atmos. Chem. Phys., 6, 5631-5648, doi:10.5194/acp-6-5631-2006, 2006.

Spracklen, D. V., Carslaw, K. S., Merikanto, J., Mann, G. W., Reddington, C. L., Pickering, S., Ogren, J. A., Andrews, E., Baltensperger, U., Weingartner, E., Boy, M., Kulmala, M., Laakso, L., Lihavainen, H., Kivekäs, N., Komppula, M., Mihalopoulos, N., Kouvarakis, G., Jennings, S. G., O’Dowd, C., Birmili, W., Wiedensohler, A., Weller, R., Gras, J., Laj, P., Sellegri, K., Bonn, B., Krejci, R., Laaksonen, A., Hamed, A., Minikin, A., Harrison, R. M., Talbot, R., and Sun, J.: Explaining global surface aerosol number concentrations in terms of primary emissions and particle formation, Atmos. Chem. Phys., 10, 4775-4793, doi:10.5194/acp-10-4775-2010, 2010.

Stier, P., Feichter, J., Kinne, S., Kloster, S., Vignati, E., Wilson, J., Ganzeveld, L., Tegen, I., Werner, M., Balkanski, Y., Schulz, M., Boucher, O., Minikin, A., and Petzold, A.: The aerosol-climate model ECHAM5-HAM, Atmos. Chem. Phys., 5, 1125-1156, doi:10.5194/acp-5-1125-2005, 2005.

Sundqvist, H.: A parameterization scheme for non-convective condensation including prediction of cloud water content, Q. J. Meteorol. Soc., 104, 677-690, 1978.

Sundqvist, H., Berge, E., and Kristiansson, J. E.: Condensation and Cloud Parameterization Studies with a Mesoscale Numerical Weather Prediction Model, Mon. Weather Rev., 117, 1641-1657, 1989.

Tanre, D., Geleyn, J.-F., and Slingo, J. M.: First results of the introduction of an advanced aerosol-radiation interaction in the ECMWF low resolution global model, Aerosols and their Climatic Effects, edited by: Gerber, H. and Deepak, A., Hampton, Virginia, 133-177, 1984.

Teichmann, C.: Climate and Air Pollution Modelling in South America with Focus on Megacities, PhD. Thesis, Reports on 
Earth System Science, Max Planck Institute for Meteorology, Hamburg, 2010.

Tiedtke, M.: A comprehensive mass flux scheme for cumulus parametrisation in large-scale models, Mon. Weather Rev., 117, 1779-1800, 1989.

University of East Anglia Climatic Research Unit, Phil Jones and Ian Harris: CRU Time Series (TS) high resolution gridded datasets. NCAS British Atmospheric Data Centre, available at: http://badc.nerc.ac.uk/view/badc.nerc.ac.uk__ATOM_dataent_1256223773328276 (last access: 30 October 2012), 2008.

Vehkamäki, H., Kulmala, M., Napari, I., Lehtinen, K. E. J., Timmreck, C., Noppel, M., and Laaksonen, A.: An improved parameterization for sulfuric acid-water nucleation rates for tropospheric and stratospheric conditions, J. Geophys. Res., 107, 4622, doi:10.1029/2002JD002184, 2002.

Vignati, E., Wilson, J. and Stier, P.: M7: An efficient sizeresolved aerosol microphysics module for large-scale aerosol transport models, J. Geophys. Res., 109, D22202, doi:10.1029/2003JD004485, 2004.
Weigum, N. M., Stier, P., Schwarz, J. P., Fahey, D. W., and Spackman, J. R.: Scales of variability of black carbon plumes over the Pacific Ocean, Geophys. Res. Lett., 39, L15804, doi:10.1029/2012GL052127, 2012.

Yu, F., Luo, G., and Ma, X.: Regional and global modeling of aerosol optical properties with a size, composition, and mixing state resolved particle microphysics model, Atmos. Chem. Phys., 12, 5719-5736, doi:10.5194/acp-12-5719-2012, 2012.

Zubler, E. M., Folini, D., Lohmann, U., Lüthi, D., Muhlbauer, A., Pousse-Nottelmann, S., Schär, C., and Wild, M.: Implementation and evaluation of aerosol and cloud microphysics in a regional climate model, J. Geophys. Res., 116, D02211, doi:10.1029/2010JD014572, 2011a.

Zubler, E. M., Lohmann, U., Lüthi, D., and Schär, C.: Intercomparison of aerosol climatologies for use in a regional climate model over Europe, Geophys. Res. Lett., 38, L15705, doi:10.1029/2011GL048081, 2011 b. 